\title{
REALISMO CRÍTICO E ESTUDOS ORGANIZACIONAIS: UMA ANÁLISE BIBLIOMÉTRICA
}

\author{
CRITICAL REALISM AND ORGANIZATIONAL STUDIES: \\ A BIBLIOMETRIC ANALYSIS
}

Recebido em 23.12.2018. Aprovado em 15.05.2019

Avaliado pelo sistema double blind review

José Willer do Prado

DOI: https://doi.org/10.12712/rpca.v13i2.27540

\section{jwprado@gmail.com}

Programa de Pós-Graduação em Administração/Universidade Federal de Lavras - Lavras/MG, Brasil

ORCID: http://orcid.org/0000-0003-3926-2406

\section{Valderí de Castro Alcântara}

valderidecastroalcantara@gmail.com

Núcleo de Estudos em Administração Pública e Gestão Social (NEAPEGS) - Lavras/MG, Brasil

Universidade do Estado de Minas Gerais (UEMG)

ORCID: http://orcid.org/0000-0002-6698-0609

\section{Alyce Cardoso Campos}

alycecardosoc@yahoo.com.br

Programa de Pós-Graduação em Administração/Universidade Federal de Lavras - Lavras/MG, Brasil

ORCID: http://orcid.org/0000-0001-6903-9542

\section{Thaísa Barcellos Pinheiro do Nascimento}

\section{thaisapinheiro35@gmail.com}

Programa de Pós-Graduação em Administração/Universidade Federal de Lavras - Lavras/MG, Brasil ORCID: http://orcid.org/0000-0002-8360-8649

\section{Resumo}

O objetivo deste artigo é analisar como se configura o campo dos estudos sobre gestão e organizações construído a partir da abordagem filosófica e sociológica do realismo crítico. Para tanto desenvolvemos uma análise bibliométrica. Apresentamos elementos centrais (autoria, periódicos, temas de estudo, artigos mais citados e principais referências) dos estudos sobre gestão e organizações construídos a partir do realismo crítico, mapeamos controvérsias científicas e desenvolvemos uma agenda de pesquisa. Concluímos que o realismo crítico potencializa o entendimento e a explicação de temas controversos dos estudos de gestão e organizações realidade social, entidades, efeitos causais, agência-estrutura e ontologia.

Palavras-chave: Gestão e Organizações. Análise Bibliométrica. Ontologia. Agenda de Pesquisa.

\begin{abstract}
The objective of this article is to analyze how the field of studies on management and organizations is constructed from the philosophical and sociological approach of critical realism. For this, we developed a bibliometric analysis. We present central elements (authorship, journals, study themes, most cited articles and main references) of management studies and organizations built on critical realism, map scientific controversies and develop a research agenda. We conclude that critical realism enhances the understanding and explanation of controversial themes of management studies and organizations such as social reality, entities, causal effects, agency structure and ontology.
\end{abstract}

Keywords: Management and Organizations. Bibliometric Analysis. Ontology. Research Agenda. 


\section{Introdução}

A partir da filosofia de Roy Bhaskar (1978) a perspectiva do realismo crítico está avançando em campos como economia, geografia, ecologia e nas ciências sociais com a teoria social realista. Há mais de uma década, Reed (2005a) chamou para uma "virada realista" também nos estudos sobre gestão e organizações. A partir de diversas propostas, debates foram travados, especialmente, entre realistascríticos e socioconstrucionistas, bem como já foram propostas aproximações (Al-Amoudi \& Willmott, 2011).

Todavia, não houve ainda uma sistematização de como se configura o campo dos estudos sobre gestão e organizações construído a partir do realismo crítico. Nesse sentido, a análise bibliométrica deste estudo tem como plano de fundo o argumento de que o realismo crítico é uma abordagem abrangente e profícua em pesquisas em administração, especialmente, por considerar diversos "domínios do real" e com isso não excluir das pesquisas diferentes componentes das relações sociomateriais, discursivas e extradiscursivas. Em se tratando da relevância do realismo crítico, Reed (2005a) informa que ele é uma filosofia que apresenta uma concepção radicalmente diferente da natureza do social - divergente do positivismo, do pós-modernismo e do pós-estruturalismo.

Estudos iniciais indicam que o realismo crítico orienta pesquisas em várias áreas do saber, incluindo contribuições para a administração, tratando de temas como sistemas de informação, estudo de caso, inovação, estratégia e empreendedorismo (Reed, 2005a; Fleetwood, 2005; Easton, 2010). E, por isso, os textos de Fleetwood (2005) e Reed (2005a) informam que o realismo crítico oferece perspectivas para os estudos das organizações e de gestão que podem orientar pesquisas empíricas sobre diversas questões.

Contudo, nos parece que em gestão e organizações a difusão da perspectiva foi "tardia" devido ao domínio primeiro do positivo e do funcionalismo e em seguida das vertentes socioconstrucionistas, com a influência das viradas linguística e pós-moderna no campo de estudos. Diante disso, buscamos realizar uma sistematização, organização e análise das pesquisas sobre gestão e organizações construídas a partir da abordagem filosófica e sociológica do realismo crítico, considerando a seguinte questão: como se configura o campo dos estudos sobre gestão e organizações construído a partir da abordagem do realismo crítico?

A partir disso, o objetivo deste artigo é analisar como se configura o campo dos estudos sobre gestão e organizações construído a partir da abordagem do realismo crítico. Para tanto justificamos essa pesquisa destacando: (a) o realismo crítico oferece contribuições relevantes quando aplicado aos estudos de gestão e organizações (Reed, 2005a, 2005b; Fleetwood, 2005, 2009); (b) não há uma sistematização ampla destes estudos; (c) uma sistematização pode contribuir para incentivar novos pesquisadores, direcionar suas publicações e temas de estudos, e, (d) a pesquisa indica uma ampla literatura internacional que pode incentivar pesquisas nos estudos organizacionais nacionais.

Dessa forma, o artigo contribui, primeiramente com a organização e sistematização dos estudos sobre gestão e organizações realizados a partir do realismo crítico oferecendo aos pesquisadores interessados uma visão geral deste campo, especialmente, para os "entrantes". Em segundo lugar, oferece uma lista de referências desde as clássicas, passando pelas mais citadas até as emergentes que podem orientar e inspirar pesquisas no campo; e, em terceiro, argumenta em prol dessa abordagem mostrando suas contribuições para os estudos de gestão e organizações, em particular, defendendo uma agenda de pesquisa realista e crítica.

\section{Breve nota sobre realismo crítico e as organizações}

Nesse breve referencial enfatizamos as seguintes questões inerentes ao estudo do realismo crítico: a ênfase na questão da ontologia; a ideia da existência de um mundo real que independe de nosso conhecimento dele; crítica às abordagens pós-modernas e pós-estruturalistas, bem como àquelas que 
conferem primazia "exagerada" à linguagem; as acusações de que o construcionismo social se tornou falacioso ao repetir que tudo é socialmente construído; e a defesa da importância da relação entre agência e estrutura.

É visível a ênfase dada pelo realismo crítico à questão da ontologia, isto é, "a maneira como pensamos que o mundo é" (Fleetwood, 2005, p. 197) e como podemos alcançar segurança em termos do "real". Esta dimensão foi perdida nas teias discursivas das teorias pós-estruturalistas (Reed, 2005a; Fleetwood, 2005) que desconsideram a questão do referente (Sayer, 2000). Nas palavras de Reed (2005a) essas teorias acreditam no reducionismo de construções linguísticas que não têm referência em um mundo objetivo independente. Por isso, segundo Reed (2005a) e Fleetwood (2005) a ontologia foi perdida nos estudos das organizações e da gestão em prol de uma autonomia ou mesmo primazia da epistemologia. Isso seria decorrente, dentre outras coisas, da virada linguística nestes estudos, especialmente nas duas últimas décadas do século passado. O realismo crítico indica, ao contrário, que a realidade não deixa de existir sem nossas descrições (Bhaskar, 1978), e, portanto, a ontologia não pode ser reduzida à epistemologia (formas e meios de produzir conhecimento sobre os diversos domínios do "real").

O argumento da carência da ontologia (e da busca pelo seu retorno) é destacado pelo maior expoente do realismo crítico, Roy Bhaskar. Desde a década de 1970, este filósofo levanta discussões nesse sentido, mesmo sendo sua obra também bastante plural e marcada por fases (Vandenberghe, 2010). Sobre as questões de ontologia, realismo e discurso, Bhaskar critica, por exemplo, em um debate realizado com Ernesto Laclau as perspectivas pós-estruturalistas. Segundo Bhaskar, estas perspectivas reduzem tudo ao nível do discurso e não concebem que o referente existe independente de sua constituição discursiva (Cf. Laclau \& Bhaskar, 1998). Nesta questão reside grande parte das críticas do realismo crítico às abordagens pós-estruturalistas, além disso, reside também no fato que dissolvem estrutura e agência em forma de discurso, perdendo o potencial analítico destas categorias. A questão da relação entre agência e estrutura é recuperada de forma mais marcante por outra realista crítica, Margaret Archer, especialmente, na sua tradução do realismo crítico para a sociologia (Archer, 1995).

No que se refere a Roy Bhaskar, Vandenberghe (2016) afirma que ele contribuiu decididamente para importantes avanços em torno da discussão da ontologia: a partir dele é possível construir uma ampla crítica ao positivismo, bem como ao construcionismo social radical.

\footnotetext{
O realismo crítico aceita sinceramente o relativismo epistêmico, mas, para evitar o irracionalismo da multiplicação de mundos, introduz uma distinção categórica entre as dimensões intransitiva (ou ontológica) e transitiva (ou epistêmica) da realidade. A dimensão intransitiva refere-se a entidades no mundo que são reais e existem independentemente do que pensamos (externalismo), enquanto a dimensão transitiva refere-se a coisas também reais, mas cuja existência depende daquilo que pensamos (internalismos). [...] Graças a este duplo foco, o realismo crítico consegue combinar e reconciliar o realismo ontológico, o relativismo epistemológico e racionalidade de julgamento. Ele é, assim, singularmente compatível com uma sociologia da ciência e da tecnologia, ao mesmo tempo que evita os excessos do (des)construcionismo radical. (Vandenberghe, 2010, p. 19-20).
}

Isso significa que não se produz conhecimento somente pelo realismo raso daquilo que pode ser experenciado, medido e comensurado, nem também a partir da visão de que somente aquilo que conhecemos é o que existe e que a realidade depende de como vemos e em que contexto vemos. Para Roy Bhaskar (1978), Margaret Archer (1995), Andrew Sayer (2000) e para os realistas críticos em geral, é preciso equilibrar as coisas e levar a sério o "real" e seus domínios.

Reed (2005a) e Fleetwood (2005; 2009) usam essas noções para criticar entendimentos como: (i) as organizações são apenas textos e discursos; (ii) que estruturas podem ser concebidas apenas como discursividade e (iii) que a dimensão material só é possível pela sua apreensão pela linguagem, portanto, não existiria a priori. Em outro sentido, os autores apresentam caminhos para pesquisas realistas que considerem questões como as relações entre estrutura e agência; a dimensão sociomaterial das 
organizações e a relação da materialidade com outras entidades como as discursivas. Considerando isso, Reed (2005a) coaduna com a defesa de uma virada realista nos estudos de gestão.

Segundo Fleetwood (2005, p. 202-203), o argumento central do realismo crítico é: "An entity may exist independently of its identification by social analysts and actors. We (i.e. all human beings) may not have discovered it". Desta forma, não podemos conhecer toda a realidade, isto é, não somos capazes de ter acesso direto e visível ao real (Sayer, 2000, Reed, 2005a). Isso leva a uma característica importante que é a falibilidade: "All theoretical descriptions, explanations and evaluations are grounded in knowledge generating and diffusion processes that are temporally and spatial located in historical and social settings that makes them fallible, contested and revisable" (Reed, 2005a, p. 1632).

O discurso e a linguagem não são descartados pelo realismo crítico, mas ele os coloca em relação a estratificação do real, assim como sinais, crenças, entendimentos, teorias e outras entidades discursivas são consideradas como parte do real ideal (Sayer, 2000; Fleetwood, 2005). Estas entidades possuem eficácia causal, possuindo efeito no comportamento e na ação.

É devido do estudo dos efeitos do discurso que na análise de discurso crítica, Norman Fairclough (2005) entende o realismo crítico como uma ontologia coerente com sua proposta. Cabe mencionar que também não há desprezo pela hermenêutica (Sayer, 2000), pois os realistas críticos concebem que o acesso do pesquisador é mediado e eles estão inseridos em contextos sócio-históricos (Sayer, 2000; Fleetwood, 2005). Portanto, como destacam Fleetwood (2005; 2009), Sayer (2000) e Reed (2005a), a ontologia do realismo crítico é aberta para diversas epistemologias e metodologias. Considerando isso, alguns autores como Al-Amoudi e Willmott (2011) concebem aproximações entre o realismo crítico e o construcionismo social.

Conforme mencionado anteriormente a questão da agência e da estrutura é relevante no realismo crítico. Para além dos extremos de delimitar as diferenças ou escolher uma em detrimento de outra, os realistas críticos indicam que "agência e estrutura também devem ser articuladas" (Sayer, 2000, p. 30). Fleetwood (2005, p. 215) complementa: "For critical realists, by contrast, agency and structure are central to their social ontology". E, nisso, uma ampliação é realizada por Margaret Archer (1995): agentes e estruturas estão em interação e as estruturas restringem ou potencializam a ação dos agentes - noções que a autora amplia a partir de Giddens e Bourdieu. Aplicando ao campo do estudo da organização e da gestão, Fleetwood (2005) entende que algumas vantagens desta abordagem é que não é preciso privilegiar uma das polaridades e marginalizar a outra, e, ainda não reifica essas categorias analíticas como fazem os positivistas e nem tão pouco as absorve como construções discursivas como fazem os estudos pós-modernos.

Finalmente, nesse breve referencial é importante lembrar que o realismo crítico abre também possibilidades para discutir a emancipação ao considerar os elementos referentes a mudança social e a contingência (Sayer, 2000). Nos autores clássicos do campo além de Bhaskar, que sob a influência marxista pensa a dialética, Archer (1995) também se volta para a ideia da transformação e da mudança (Vandenberghe, 2016). Com isso é possível um fértil diálogo entre a ontologia do realismo crítico e as abordagens dos estudos críticos em administração. Neste diálogo, é possível atuar nas lacunas daquilo que Fleetwood (2005) e Reed (2005a) colocam como falta de clareza, imprecisão e deslizamento conceitual dos estudos organizacionais. Além disso, é necessário buscar para os estudos das organizações e de gestão o que foi esquecido por muito tempo: a ontologia (Sayer, 2000; Reed, 2005a; 2005b; Fleetwood, 2005; Easton, 2010; Tsang, 2014).

\section{Procedimentos metodológicos}

Este estudo é definido como bibliométrico e pode auxiliar pesquisadores a encontrarem literatura relevante, concentração de pesquisas e temas em que os estudos realistas-críticos estão focados, dentre outros elementos (Pinto, Serra, \& Ferreira, 2014; Prado et al., 2016). 
Uma bibliometria é relevante e útil de diferentes formas, para além da contribuição para o conhecimento em determinada área ou campo. De modo prático, conhecer os autores e referências mais citadas proporciona conhecimento sobre quem e quais textos é relevante ler, estudar e citar; conhecer as instituições e países onde os estudos são concentrados pode ser relevante para a realização de intercâmbios e pesquisas comparativas, por exemplo. Identificar palavras-chave e temas mais usadas pode direcionar as pesquisas para problemáticas mais aceitas pelos periódicos, ou ainda, conhecer as palavraschaves e temas menos citados abre espaço para novos estudos (gaps de pesquisa). Finalmente, encontrar periódicos que concentram as publicações pode oferecer ao pesquisador maiores possibilidades de publicação de seu texto. Portanto, além das contribuições científicas, as pesquisas bibliométricas colaboram com o cotidiano científico que envolve, entre outras coisas, estudar, ler, citar e publicar artigos.

No que tange aos procedimentos metodológicos, para dar transparência a construção das etapas foi adaptado o framework (Figura 1) desenvolvido por Prado et al. (2016). Este protocolo estabelece etapas a serem seguidas pelo pesquisador para o planejamento, a busca, a seleção, a organização e a análise do corpus do estudo.

Figura 1 - Framework de organização da pesquisa

\begin{tabular}{|c|c|c|c|}
\hline Etapa & Procedimento & & Descrição \\
\hline \multirow{9}{*}{ Banco dos dados } & \multirow{3}{*}{ Campo em estudo } & 1.1 & Escolha da(s) base(s) científica(s) ou periódico(s) \\
\hline & & 1.2 & Delimitação dos termos que representam o campo \\
\hline & & 1.3 & Operacionalização da busca e seleção dos artigos \\
\hline & \multirow{6}{*}{$\begin{array}{c}(2) \\
\text { Seleção e } \\
\text { organização dos } \\
\text { dados }\end{array}$} & 2.1 & Download das referências - software EndNote \\
\hline & & 2.2 & Download das referências em formato planilha eletrônica \\
\hline & & 2.3 & Download das referências para utilização no CiteSpace \\
\hline & & 2.4 & Organização das referências no EndNote \\
\hline & & 2.5 & Organização de matriz de análise em planilha eletrônica \\
\hline & & 2.6 & Importação dos dados em outros softwares de análise \\
\hline \multirow{14}{*}{$\begin{array}{c}\text { Análise e } \\
\text { interpretação }\end{array}$} & \multirow{10}{*}{$\begin{array}{c}\text { (3) } \\
\text { Research front (Frente } \\
\text { de Pesquisa) }\end{array}$} & 3.1 & Análise do volume e tendências temporais \\
\hline & & 3.2 & Análise da autoria (mais profícuos) dos artigos \\
\hline & & 3.3 & Análise dos artigos mais citadas \\
\hline & & 3.4 & Análise do país dos autores \\
\hline & & 3.5 & Análise dos periódicos \\
\hline & & 3.6 & Análise das categorias \\
\hline & & 3.7 & Análise das palavras-chave \\
\hline & & 3.8 & Identificação de métodos e técnicas de pesquisa \\
\hline & & 3.9 & Identificação de teorias mobilizadas \\
\hline & & 3.10 & Descrição, estudo das relações e tendências \\
\hline & \multirow{4}{*}{$\begin{array}{c}\text { (4) } \\
\text { Base intelectual (Base } \\
\text { Intelectual) }\end{array}$} & 4.1 & Análise da journal co-citation network \\
\hline & & 4.2 & Análise da author co-citation network \\
\hline & & 4.3 & Análise da reference co-citation network. \\
\hline & & 4.4 & Descrição, estudo das relações e tendências \\
\hline
\end{tabular}

Fonte: Adaptado de Prado et al. (2016).

Optamos por realizar a busca a partir da base de dados Web of Science, da Thomson Reuters. A base é uma das mais completas no que se refere à organização da produção científica e é utilizada por diferentes estudiosos como referência (Prado et al., 2016). Na primeira etapa e no procedimento 1 buscamos identificar os termos que poderiam representar nosso campo de estudo (rótulos de campo), tendo em vista que o realismo crítico pode ser designado por termos como abordagem, perspectiva, análise, virada e outras possibilidades (Tabela 1).

Com os termos procedemos as buscas em inglês e português. Estas, por sua vez, foram realizadas empregando as expressões entre aspas no campo tópico da Web of Science. Ou seja, o termo deveria constar no título, resumo ou palavras-chave do artigo - entendendo que dessa forma o artigo possui a temática como central em seu desenvolvimento. Foram considerados apenas documentos em formato de artigo científico publicado em periódico (na Web of Science representados pelos campos article e review. Optamos 
por todo o período de tempo disponível na base no momento, isto é, de 1945 à 2017 (ano de realização da busca). E, foram escolhidas as áreas de estudo: management (que inclui os estudos organizacionais na base delimitada), business e public administration - para todas essas áreas utilizamos a denominação estudos sobre gestão e organizações.

Ao final do processo de delimitação foram encontrados 160 artigos. A Tabela 1 apresenta o número de estudos encontrados por termo e por categoria da Web of Science).

Tabela 1 - Frequência de artigos por termo e categoria (área) da Web of Science

\begin{tabular}{lcccc}
\hline \multirow{2}{*}{ Termo da busca } & \multicolumn{4}{c}{ Categoria da Web of Science } \\
\cline { 2 - 5 } & Management & Business & Public Administration & Áreas Conjuntas \\
\hline realist perspective & 27 & 10 & 2 & $\mathbf{3 1}$ \\
critical realist & 72 & 24 & 4 & $\mathbf{8 2}$ \\
critical realism & 112 & 39 & 8 & $\mathbf{1 3 4}$ \\
realist turn & 3 & 3 & 0 & $\mathbf{3}$ \\
realist analysis & 5 & 0 & 2 & $\mathbf{7}$ \\
\hline Termos Conjuntos & $\mathbf{1 3 4}$ & $\mathbf{5 1}$ & $\mathbf{1 1}$ & $\mathbf{1 6 0}$ \\
\hline
\end{tabular}

Fonte: Elaborada pelos autores (nos totais Termos Conjuntos e Áreas Conjuntas não estão incluídos os duplicados).

Vale notar que a coluna Áreas Conjuntas não representa a soma em cada linha, uma vez que, um artigo pode ser classificado de forma conjunta nas áreas, por exemplo, em management e business. A linha Termos Conjuntos também não representa a soma das buscas individuais dado que os diversos termos podem identificar o mesmo artigo. Por isso, o sistema de busca organizado destaca as diversas formas de se referir ao "realismo crítico". Após os filtros, delimitação e desconsiderando os artigos duplicados foram encontrados 160 textos diferentes.

Realizamos o download e organização das referências para diferentes formatos como os softwares EndNote, planilha eletrônica e CiteSpace. Foi organizada a matriz de análise em planilha eletrônica e foi realizada a importação dos dados em outros softwares.

Para a análise e interpretação dos resultados, apresentamos características bibliométricas diversas (autoria, artigos mais citados, periódico, países dos autores, palavras-chave e outros) em formato de gráficos, tabelas de frequência e redes. Em cada caso buscamos sintetizar os resultados e apresentar relações/tendências observadas. Para apresentações de redes e relações adotamos os procedimentos descritos por Chen $(2004,2006)$ no que tange ao uso do software CiteSpace para visualizar pontos de virada intelectual, tendências emergentes e padrões. Por meio disso analisamos a Frente de Pesquisa e a Base Intelectual (Chen, 2006).

Segundo Chen (2006, p. 362), a Frente de Pesquisa é representada pelos artigos mais citados que acessamos por meio da $W$ eb of Science. Nesse caso, analisamos o volume e tendências temporais, autoria e os autores mais profícuos, artigos mais citados, país dos autores, periódicos, categorias da Web of Science, palavraschave, métodos e técnicas de pesquisa aplicados, teorias mobilizadas, estudo das relações e tendências.

Por sua vez, a Base Intelectual é representada no Citespace pelas redes de cocitação (journal co-citation network, author co-citation network e reference co-citation network), portanto, pelos periódicos, autores e referências que foram mais cocitados pelos artigos que mapeamos na Web of Science. Dado que as publicações científicas podem ser analisadas por meio de seus padrões que revelam um "mapa" dos campos científicos e das suas relações, o entendimento da Frente de Pesquisa e da Base Intelectual ganha relevância. Assim, os procedimentos 3 e 4 da Figura 1 orientou a mapear os artigos, autores, periódicos e outros elementos mais citados, com atenção as redes de cocitação e não somente de citação (Chen, 2006). Finalmente, Chen (2006) demostra que por meio de citações e cocitações tem-se acesso às tendências de pesquisas e interrelações existentes em um campo de estudo - o que é feito também por meio de uma visualização gráfica em redes. 


\section{Caminhos da virada realista-crítica em gestão e organizações}

\section{Tendências da abordagem realista crítica}

A difusão da abordagem realista crítica nos estudos de gestão e organizações tem origem na década de 1990, no entanto, observamos um crescimento marcante de artigos somente a partir de 2001 e de 2005. Em 2001, foram publicados artigos com alto número de citações como Mingers (2001) e Reed (2001). Adiante, em 2005 foram publicados também artigos de grande disseminação como Fairclough (2005), Fleetwood (2005) e Reed (2005a).

Esses cinco artigos foram importantes na medida em que Mingers (2001) demostra a relevância do realismo crítico com ênfase no estudo em sistemas de informação, Reed (2001) mostra que questões como organização, confiança e controle podem ser melhor explicadas por meio de uma abordagem realista crítica, e, Fairclough (2005), abre um grande campo de pesquisa ao mostrar que os pesquisadores focados em linguagem e discurso (muitos daqueles que enfatizam a "virada linguística") podem também se beneficiar e aumentar a compreesão do discurso a partir do realismo crítico. Por sua vez, os textos de Fleetwood (2005) e Reed (2005a) funcionam dentro daquilo que Vandenberghe e Corrêa (2016) entendem como a forma de "mover a ciência" por meio da proposta de "viradas", pois são textos que buscam consolidar movimentos acadêmicos e lançam "manifestos" em busca de formar redes: de pesquisadores em realismo crítico.

Fleetwood (2005) é exemplo disso ao defender uma ontologia realista crítica para os estudos organizacionais e de gestão fazendo contraposições à abordagens socioconstrucionistas e posmodernistas (que ele chama de virada cultura, linguística, pos-estrutural e pós-moderna). Nesse processo, o autor indica limitações de autores influentes no campo de estudos organizacinais como Weick, Knights, Willmott, Alvesson, Deetz, Gergen e outros. Fleetwood (2005) defende que o realismo crítico é uma abordagem mais fecunda.

Reed (2005a) lança uma chamada/manifesto e síntese da "virada realista" nos estudos organizacionias e de gestão, bem como destaca críticas a uma ontologia construcionista social e uma epistemologia pósmodernista. Para Reed (2005a) a "virada realista" é uma oportunidade de renovação do campo. Uma nota importante é que antes deste artigo, Reed publicou em 1997 um trabalho também bastante referenciado em que faz uma crítica as aborgens pós-modernas por apagam as categorias "agência" e "estrutura", mostrando que o realismo crítico supera as visões unilaterais sem desconsiderar a importância da relação agência-estrutura (Reed, 1997). Na Figura 2 apresentamos a evolução e tendência das publicações por ano e indicamos os artigos mencionados neste tópico (que foram promissores nessa discussão), observando que os anos omitidos $(1993,1994,1995)$ na horizontal são em decorrência da inexistência de publicações na Frente de Pesquisa e omitimos 2017 para não impactar na tendência (no momento da seleção dos dados o ano ainda estava incompleto). 
Figura 2 - Evolução e tendência das publicações por ano (1992-2016)

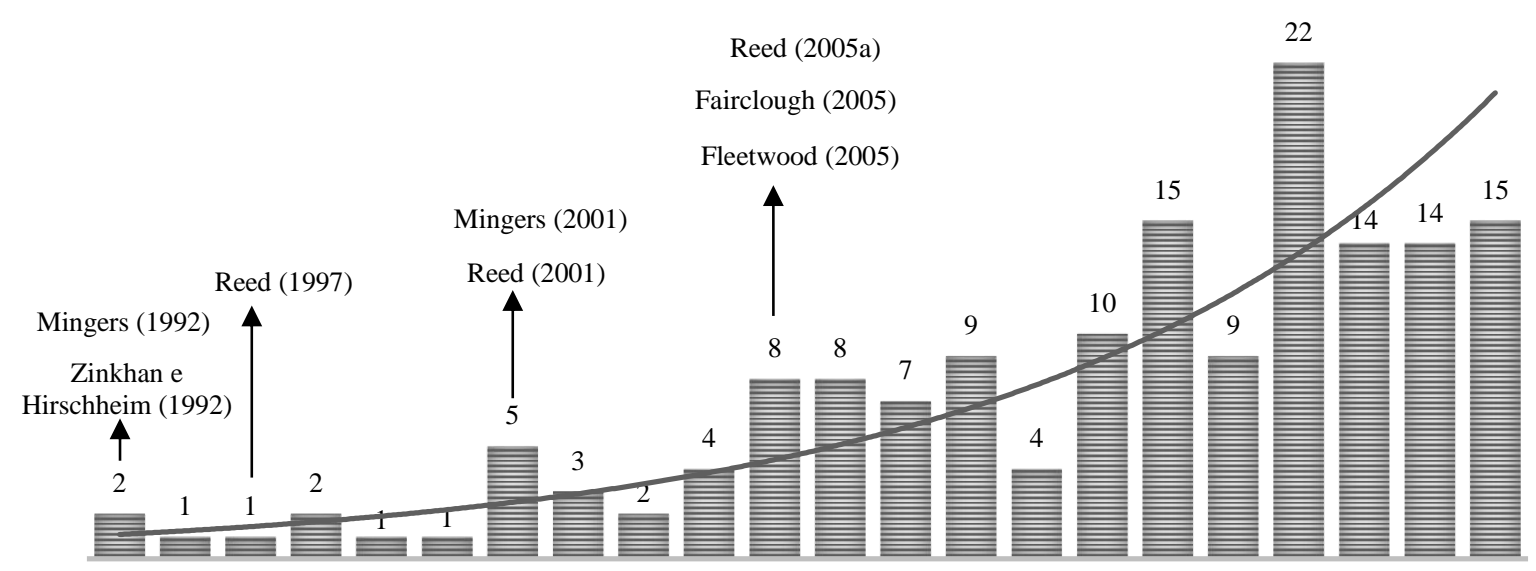

1992199619971998199920002001200220032004200520062007200820092010201120122013201420152016

Fonte: Elaborada pelos autores.

Os textos em destaque na Figura 2 mostram que o realismo crítico ganhou força, inicialmente, em oposição a uma ontologia construcionista social (radical) e uma epistemologia pós-modernista. De forma geral, no que se refere às tendências temporais constatamos que a abordagem filosófica e sociológica do realismo crítico aplicada a este campo está, mesmo com as oscilações, em ritmo de crescimento. $\mathrm{Na}$ década de 1990, os primeiros artigos encontrados na nossa busca são de 1992, a saber: Zinkhan e Hirschheim (1992) citado 33 vezes e Mingers (1992) citado 13 vezes. Estes foram publicados, respectivamente, no Journal of Marketing e no Systems Practice. Após isso há um gap e somente em 1996 e 1997 foram publicados outros artigos (Figura 2). Os textos da década de 1990 revelam produções acadêmicas voltadas para a aplicação do realismo critico de forma multidisciplinar. Assim, variam de pesquisas aplicadas em áreas como marketing (Zinkhan \& Hirschheim, 1992), sistemas de informação (Mingers, 1992) e debates sobre agência/estrutura (Reed, 1997).

É possível observar também uma quantidade de artigos destoantes publicados no ano de 2013 (22 no total). Ao buscar as explicações, encontamos que foi em decorrência do periódico Management Information Systems Quarterly (MIS Quartely) que publicou 9 trabalhos. Tal quantidade foi fruto da edição especial (Volume 37, edição 3: Special Issue: Critical Realism in IS Research). Destacamos que a publicação de uma edição especial perpassa pela consolidação de uma possível "virada" e é reflexo da institucionalização do campo.

\section{Autores e artigos da frente de pesquisa}

No que tange a autoria dos artigos a partir dos pesquisadores mais profícuos da Frente de Pesquisa, são destaques: Mingers (9 artigos), Mutch (7), Tsang (7), Reed (5), Easton (4), Fleetwood (4), Hodgkinson (4), Volkoff (4) e Willmott (4) - não importando a ordem de autoria ou coautoria. Apesar de inseridos na Frente de Pesquisa não significa que todos estes autores argumentem em favor do realismo crítico como é o caso de Hugh Willmott, autor que faz parte de controvérsias no campo, portanto, nem todos estes autores são "simpáticos" ao realismo crítico. O caso de Willmott e seu artigo de 2005 (Willmott, 2005) ilustra isso.

No geral, estes 9 autores (Mingers, Mutch, Tsang, Reed, Easton, Fleetwood, Hodgkinson, Volkoff e Willmott) foram citados 444 vezes e participaram da construção de 48 artigos, portanto, o equivalente à $30,00 \%$ do total de artigos da nossa amostra selecionada, relevando que eles possuem uma forte presença no campo. O autor mais profícuo, John Mingers, é autor do artigo mais citado da Frente de Pesquisa: Combining IS research methods: Towards a pluralist methodology de 2001, que foi citado 283 vezes na Web of Science. Além disso, os artigos mais citados de cada um dos nove autores em destaque mostram a amplitude de temas e debates em variadas áreas: sistema de informação, empreendedorismo, tecnologia, 
debates teóricos amplos sobre ontologia, replicação de teorias, relevância e rigor, e, debates envolvendo perspectivas realistas, socioconstrucionistas e pós-estruturalistas. $\mathrm{Na}$ Tabela 2 apresentamos os artigos mais citados da amostra de artigos - citações (Cit.) na Web of Science.

Tabela 2 - Artigos centrais da Frente de Pesquisa

\begin{tabular}{|c|c|c|c|c|}
\hline Título do artigo & Autor(es) & Periódico & Ano & Cit. \\
\hline $\begin{array}{l}\text { 1. Combining IS research methods: Towards a pluralist } \\
\text { methodology }\end{array}$ & Mingers & $\begin{array}{l}\text { Information Systems } \\
\text { Research }\end{array}$ & 2001 & 283 \\
\hline $\begin{array}{l}\text { 2. Replication and theory development in organizational science: } A \\
\text { critical realist perspective }\end{array}$ & Tsang e Kwan & $\begin{array}{l}\text { Academy of Management } \\
\text { Review }\end{array}$ & 1999 & 247 \\
\hline $\begin{array}{l}\text { 3. Peripheral vision: discourse analysis in organization studies: } \\
\text { The case for critical realism }\end{array}$ & Fairclough & Organization Studies & 2005 & 205 \\
\hline 4. Critical realism in case study research & Easton & $\begin{array}{l}\text { Industrial Marketing } \\
\text { Management }\end{array}$ & 2010 & 122 \\
\hline 5. A cognitive model of innovation & Nightingale & Research Policy & 1998 & 107 \\
\hline $\begin{array}{l}\text { 6. In praise of duality and dualism: Rethinking agency and } \\
\text { structure in organizational analysis }\end{array}$ & Reed & Organization Studies & 1997 & 107 \\
\hline $\begin{array}{l}\text { 7. Bridging the qualitative-quantitative divide: Guidelines for } \\
\text { conducting mixed methods research in information systems }\end{array}$ & $\begin{array}{l}\text { Venkatesh, Brown e } \\
\text { Bala }\end{array}$ & MIS Quarterly & 2013 & 99 \\
\hline 8. Technological embeddedness and organizational change & $\begin{array}{l}\text { Volkoff, Strong e } \\
\text { Elmes }\end{array}$ & Organization Science & 2007 & 98 \\
\hline 9. A critical realist approach to institutional entrepreneurship & Leca e Naccache & Organization & 2006 & 93 \\
\hline 10. Organization, trust and control: $A$ realist analysis & Reed & Organization Studies & 2001 & 88 \\
\hline $\begin{array}{l}\text { 11. Ontology in organization and management studies: } A \text { critical } \\
\text { realist perspective }\end{array}$ & Fleetwood & Organization & 2005 & 86 \\
\hline $\begin{array}{l}\text { 12. Reflections on the 'realist turn' in organization and management } \\
\text { studies }\end{array}$ & Reed & $\begin{array}{l}\text { Journal of Management } \\
\text { Studies }\end{array}$ & 2005 & 73 \\
\hline $\begin{array}{l}\text { 13. Understanding organization-enterprise system fit: a path to } \\
\text { theorizing the information technology artifact }\end{array}$ & Strong e Volkoff & MIS Quarterly & 2010 & 72 \\
\hline $\begin{array}{l}\text { 14. Entrepreneurship and epistemology: The philosophical } \\
\text { underpinnings of the study of entrepreneurial opportunities }\end{array}$ & Alvarez e Barney & $\begin{array}{l}\text { Academy of Management } \\
\text { Annals }\end{array}$ & 2010 & 67 \\
\hline $\begin{array}{l}\text { 15. The contribution of critical realism as an underpinning } \\
\text { philosophy for } O R / M S \text { and systems }\end{array}$ & Mingers & $\begin{array}{l}\text { Journal of the Operational } \\
\text { Research Society }\end{array}$ & 2000 & 65 \\
\hline
\end{tabular}

Fonte: Elaborada a partir dos dados da Web of Science.

Notamos a relevância de textos como Fairclough (2005), Reed (1997), Mingers (2001), Fleetwood (2005) e Reed (2005a). Mingers (2001), o estudo mais citado da Frente de Pesquisa, é aplicado na área de sistema de informação; Tsang e Kwan (1999) na perspectiva realista crítica estuda o papel desempenhado pela replicação no desenvolvimento teórico; Fairclough (2005) trata da análise discurso crítica a partir de uma ontologia realista crítica; Easton (2010) apresenta essa visão para o estudo de caso; Nightingale (1998) estuda o papel do conhecimento tácito na mudança técnica e como o conhecimento científico é usado na inovação; e, Reed (1997) discute as relações agência-estrutura a partir da ótica realista crítica.

Com estes exemplos, constatamos de forma geral a pluralidade de áreas exploradas, debates teóricos e perspectivas metodológicas com textos focados em discussões sobre métodos de pesquisa mistos em sistemas de informação, integração tecnológica e mudança organizacional, empreendedorismo institucional, organização, confiança e controle, sistemas e tecnologia da informação e empreendedorismo. Pela Tabela 2, quanto aos periódicos em que os artigos centrais da Frente de Pesquisa foram publicados, são destaques aqueles com foco em teorias organizacionais como Organization Studies (Reed, 1997, 2001; Fairclough, 2005) e Organization (Fleetwood, 2005; Leca \& Naccache, 2006).

Outros periódicos que revelam a interdisciplinaridade e áreas de aplicação (sistemas de informação, gestão, marketing, etc.) são: Academy of Management Review (AMR), Industrial Marketing Management e Information Systems Research. Do ponto de vista operacional apresentado na metodologia deste artigo, os textos da Tabela 2 representam uma importante via de acesso às pesquisas em gestão e organizações sob 
a ótica do realismo crítico: são textos essenciais para o desenvolvimento de novas pesquisas neste campo. A Tabela 2 também cumpre o propósito de direcionar pesquisadores "entrantes" para temas específicos como tecnologia, inovação, estudos organizacionais e empreendedorismo a partir do realismo crítico.

Sobre as instituições com maior produção de artigos, é destaque Lancaster University, University of Warwick, Cardiff University, University of London e University of Cambridge. Isso indica de início que a maioria dos pesquisadores que aplicam a abordagem filosófica do realismo crítico nas ciências administrativas são ingleses. Tal questão pode ser verificada na análise dos países dos autores: 89 artigos são assinados por primeiros autores ingleses, se localizando à frente dos norte-americanos com 23 artigos e dos demais países mais relevantes como Austrália (14), País de Gales (10), Canadá (8), França (6) e Finlândia (5), entre outros.

É notório que a maioria das pesquisas seja desenvolvida na Inglaterra, especialmente, pelo fato do percursor, Roy Bhaskar ser britânico. Margaret Archer, que apresenta uma visão sociológica do realismo crítico também é britânica. Corrobora isso a passagem Pimentel (2012, p. 44): "o realismo crítico é uma vertente específica da filosofia da ciência relativamente ainda pouco difundida, parecendo ter pouca dispersão fora do Reino Unido". Para Vandenberghe (2010, p. 15): "nem o trabalho de Bhaskar nem a teoria morfogenética de Archer parecem ser bem conhecidos fora do Reino Unido". Pela concentração das publicações está pesquisa confirma isso. Também são elementos que destacam a hegemonia britânica o fato que autores da Frente de Pesquisa como Mingers, Fairclough, Easton e Fleetwood serem britânicos. Como é comum em vários estudos indicar que a "ciência fala inglês", neste caso, os estudos realistas críticos em gestão e organizações falam até o momento o "inglês britânico".

\section{Difusão da abordagem realista crítica}

Os 160 artigos mapeados foram publicados em 71 diferentes periódicos. A Tabela 3 apresenta os dez periódicos com maior número de artigos e também destaca o respectivo fator de impacto (JCR). Com destaque, os 10 periódicos mais profícuos publicaram 47,50\% do total de artigos, revelando concentração das publicações, em especial, nos periódicos Organization Studies (14 artigos), Organization (13) e MIS Quarterly (11).

Tabela 3 - Periódicos mais profícuos da Frente de Pesquisa

\begin{tabular}{lllll}
\hline \multicolumn{1}{c}{ Periódico } & N. & Perc. \% & FI 2016 & ISSN \\
\hline Organization Studies & 14 & 8,75 & 2,721 & $0170-8406$ \\
Organization & 13 & 8,13 & 1,901 & $1350-5084$ \\
MIS Quarterly & 11 & 6,88 & 4,901 & $0276-7783$ \\
Human Relations & 7 & 4,38 & 2,244 & $0018-7267$ \\
Industrial Marketing Management & 7 & 4,38 & 2,095 & $0019-8501$ \\
Information and Organization & 7 & 4,38 & 1,958 & $1471-7727$ \\
Journal of the Operational Research Society & 5 & 3,13 & 1,000 & $0160-5682$ \\
Academy of Management Review & 4 & 2,50 & 8,612 & $0363-7425$ \\
International Small Business Journal & 4 & 2,50 & 2,741 & $0266-2426$ \\
Strategic Management Journal & 4 & 2,50 & 3,893 & $0143-2095$ \\
\hline Soma parcial & $\mathbf{7 6}$ & $\mathbf{4 7 , 5 0}$ & FI & Médio \\
\hline Artigos publicados em outros periódicos & 84 & 52,50 & $\mathbf{3 , 2 0 6}$ \\
\hline Total de artigos & $\mathbf{1 6 0}$ & $\mathbf{1 0 0 , 0 0}$ & \\
\hline Nota: "N." denota a frequência (número) de artigos; "Perc. \%” o percentual respectivo; "FI 2016" o fator de impacto sem \\
autocitação (JCR selecionado para a categoria management no ano de 2016; Web of Science). \\
\hline Fonte: Elaborada a partir dos dados da Web of Science.
\end{tabular}

Fonte: Elaborada a partir dos dados da Web of Science.

Os periódicos Organization Studies (14 artigos) e Organization (13) são os principais divulgadores da abordagem realista crítica no estudo de organizações e gestão, além do MIS Quarterly (11) que é um periódico especializado em debates sobre tecnologia da informação e sistemas de informações gerenciais. $\mathrm{Na}$ Organization Studies foram publicados alguns dos artigos mais citados do campo e já apresentados aqui 
como Fairclough (2005), Reed $(1997,2001)$. Nesse periódico foi publicado também o texto de AlAmoudi e Willmott (2011) que propõe convergências entre o socioconstrucionismo e o realismo crítico.

$\mathrm{Na}$ Organization também foram publicados alguns dos artigos mais citados da Frente de Pesquisa como Leca e Naccache (2006) e Fleetwood (2005). Adiante, na MI Quarterly foram publicados os textos Venkatesh, Brown e Sala (2013) e Strong e Volkoff (2010) focados em sistemas e tecnologias da informação. No Human Relations, apesar de publicar 7 artigos e ser um periódico renomeado, não foi publicado nenhum artigo de grande repercussão sobre realismo crítico na nossa Frente de Pesquisa. No Industrial Marketing Management foi publicado o trabalho de Easton (2010) focado no método do estudo de caso sob a ótica realista crítica e aplicada ao marketing. $\mathrm{Na}$ Academy of Management Review foi publicado o segundo artigo mais citado da Frente de Pesquisa: Tsang e Kwan (1999). O artigo mais citado, Mingers (2001), foi publicado na Information Systems Research (único do periódico na amostra).

Quando analisamos as categorias em que os periódicos são indexados na Web of Science, constatamos uma diversidade de áreas, revelando a multidisciplinaridade. Mesmo que a pesquisa tenha sido filtrada em management, business e public administration, apareceram artigos que também são indexados (conjuntamente) em ciência da informação, pesquisa operacional, ecologia, estudos feministas, ética, ciências políticas, ciências sociais e outras áreas.

Especificamente, sobre as áreas de nossa busca, a saber, management, business e public administration, destacamos que em administração pública a abordagem ainda é incipiente (o primeiro artigo foi publicado em 2003 e não houve tendência de crescimento) com um número muitas vezes inferior de artigos do que em management e business. Portanto, da nossa delimitação inicial observamos que a área em que o realismo crítico está sendo menos aplicado é em administração pública. Finalmente, por meio da análise dos periódicos e categorias, observamos também que as publicações em periódicos de negócios relacionados com marketing, gestão de pequenas empresas, negócios familiares, gestão de negócios e outros, ainda possuem um número relativamente menor de artigos, sendo que a abordagem do realismo crítico tem mais campo nos periódicos focados em estudos e teorias organizacionais.

\section{Palavras e temas dos estudos}

Analisamos as palavras-chave tendo em vista revelar as principais temáticas discutidas a partir do realismo crítico nos estudos de gestão e organizações. Na Figura 3, a palavra-chave "critical realism” (103 vezes) foi plotada, mas sabe-se a priori que dado ela ter sido usada como palavra para a busca era previsível que ela tivesse uma frequência maior que as demais (isso se aplica a outras palavras como perspective e realism). Inicialmente, observamos que diversas palavras-chave são importantes para o entendimento do realismo crítico aplicado aos estudos sobre organizações e gestão e, indicam direcionamentos de pesquisas já consolidados ou em consolidação: ciência (24 vezes), desempenho (15), conhecimento (14), epistemologia (14), sistemas (14), inovação (14), organização (14), ontologia (14), trabalho (14), tecnologia (14), trabalho (13), discurso (10), metodologia (10), filosofia (9), agência (9), estudo de caso (9), poder (8), crítica (8), redes (6) e paradigma (6). Outras palavras-chave que apareceram apenas 5 vezes (estão presentes na Figura 3) que também são relevantes: resistência, tomada de decisão, identidade, empreendedorismo, transformação, tecnologia da informação, governança, estruturação, reflexividade, pesquisas em sistema de informação, mecanismos, análise organizacional, implementação e construtivismo. 


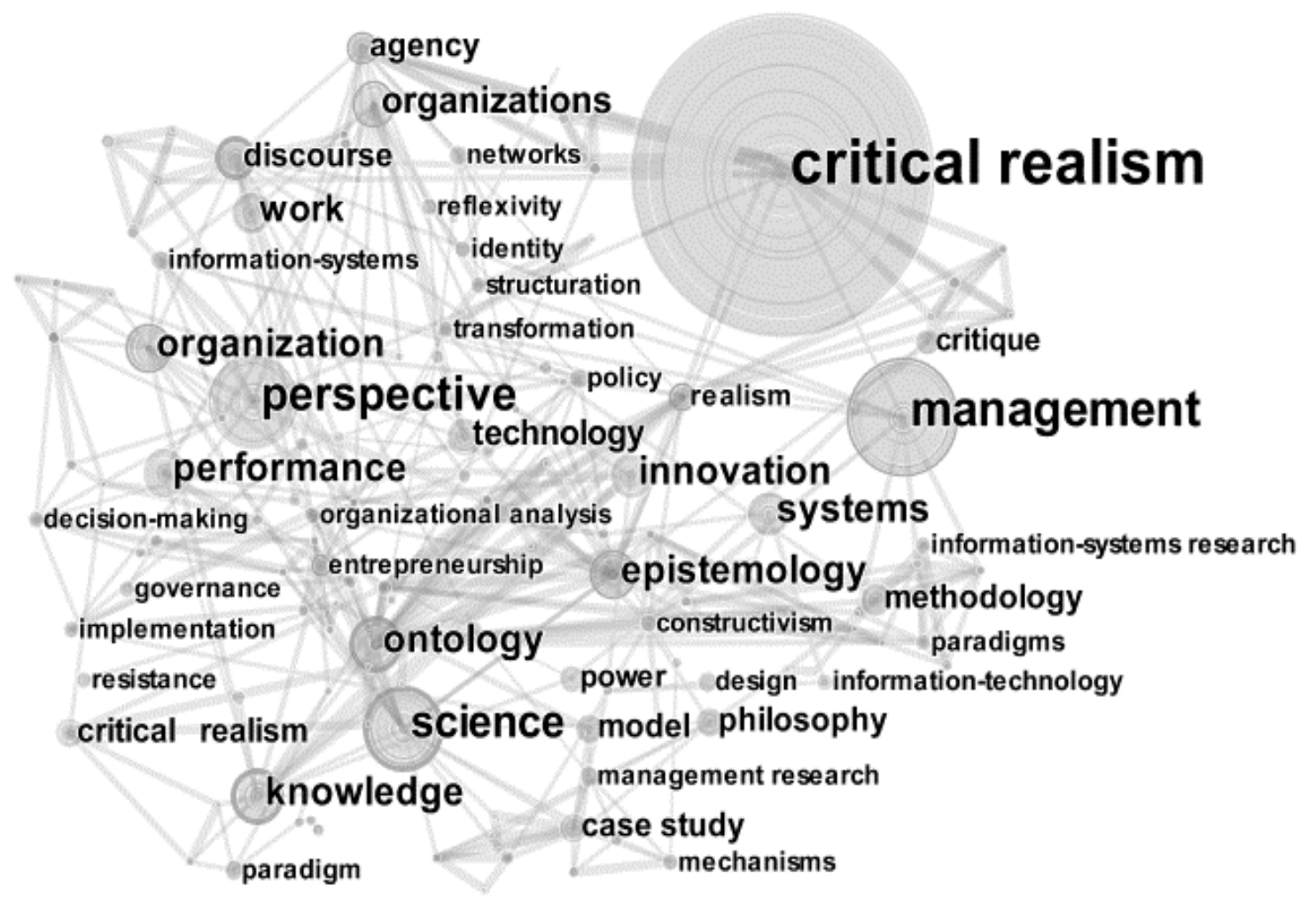

Fonte: Elaborada pelos autores.

Nota: Na Figura 3 aparecem palavras-chave com frequência igual ou superior à 5. Na rede utilizamos no software CiteSpace dos algoritmos de "poda" Pathfinder e "Pruning Sliced networks" de 5 (Chen, 2006).

Observamos que algumas palavras denotam diretamente debates na administração em termos de áreas e questões específicas como desempenho, inovação, sistemas, trabalho, tecnologia e redes. No que se refere a isso, como já observamos, existe uma forte tendência de textos que tratam de sistemas de informação e tecnologia. Outras palavras-chave revelam discussões sobre questões filosóficas e sociológicas como agência, ontologia, conhecimento, epistemologia, crítica e paradigma (Reed, 2005a, 2005b; Fleetwood, 2005, 2009; Easton, 2010). Uma das questões centrais do realismo crítico é o debate sobre ontologia, pois o diferencial primordial do realismo crítico a partir de Bhaskar (1978) é destacar a importância fundamental dele para as ciências (Fleetwood, 2005; Reed, 2005a).

O debate sobre agência e estrutura também se tornou central contra as concepções que diluem essas categorias (Fleetwood, 2005). Nisso se tornam mais importantes as contribuições de Archer (1995). Para além de Bhaskar e em diálogo com Giddens e Bourdieu, dentre outros, a autora elaborou sua própria forma de conceber as relações entre agência-estrutura, a abordagem morfogenética - são palavras-chave destas questões: reflexividade, estruturação e agência.

Em destaque, questões mais "amplas" acompanham as publicações em gestão e organizações a partir do realismo crítico desde os primeiros artigos. Já nos trabalhos publicados em 1992 (2 artigos) são palavraschave: ontologia, realismo e epistemologia. No final da década de 1990 aparecem com mais frequência outras como conhecimento e agência. Outra questão que também marca o campo até hoje é a contraposição (recentemente busca de diálogos), por um lado, ao positivismo, e, por outro ao pósmodernismo e ao socioconstrucionismo (radical). 
Observamos também que problemáticas metodológicas são discutidas com ênfase especialmente para os estudos de caso. Um dos trabalhos que mais trata disso é Easton (2010), que é o quarto artigo mais citado da Frente de Pesquisa. O autor argumenta que o estudo de caso sob a perspectiva do realismo crítico representa uma posição coerente e rigorosa de pesquisa, mais avançada que as perspectiva positivista e interpretativista do estudo de caso. Outro autor, Tsang (2014), também enfrenta a questão da cientificidade e legitimidade do estudo de caso e argumenta que a visão do realismo crítico é mais promissora e fecunda. Para Easton (2010) e Tsang (2014) com o realismo crítico, o estudo de caso se torna importante tanto para generalizações empíricas quanto teóricas e o teste de teorias.

Finalmente, notamos que no período de 1992 a 2017 algumas das discussões sobre conhecimento, epistemologia e ontologia se mantém presentes, sendo, portanto, um "núcleo duro" do campo, pois alguns destes temas são constitutivos dos debates a partir do realismo crítico de Roy Bhaskar. Isso faz mais sentido quando Vandenberghe (2016, p. 179) argumenta que Bhaskar "trouxe de volta a ontologia".

\section{Agenda de estudos}

Com a Figura 4 apresentamos temas e grupos de estudos nas pesquisas por meio de palavras-chave que foram citadas 1 ou 2 vezes apenas, isto é, que houve alguma discussão mais ainda sem consolidação considerando todo o período de tempo. Na Figura 4, observamos alguns grupos potenciais de trabalhos.

Figura 4 - Temas e grupos de estudos potenciais nas pesquisas

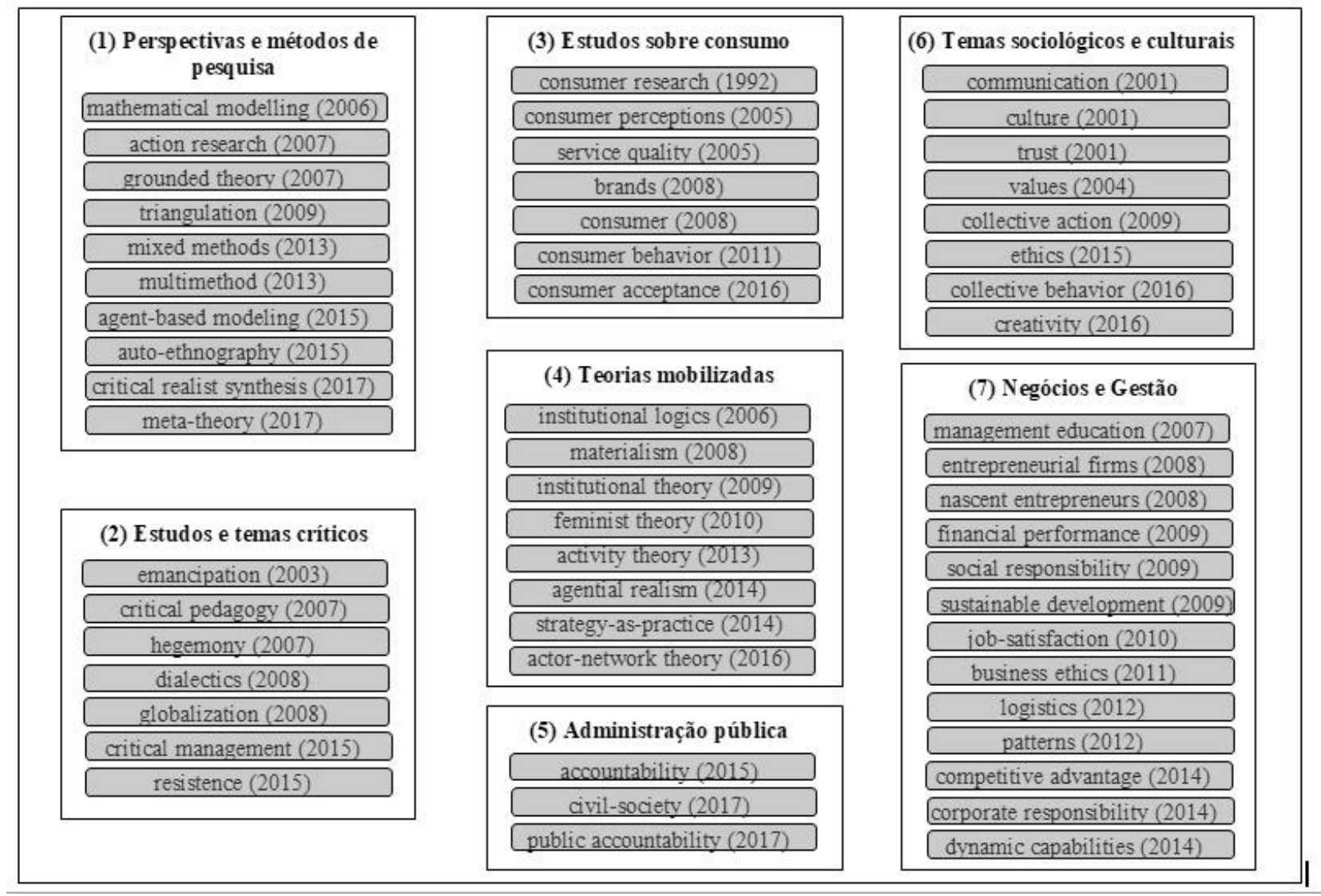

Fonte: Elaborada pelos autores.

No que se refere a (1) Perspectivas e métodos de pesquisa, destacamos que a concepção do realismo crítico supera as dicotomias entre métodos quantitativos e qualitativos em prol da busca por explicações que sejam substantivas. Portanto, aparecem como temas de pesquisas que compõe nossa agenda futura possibilidades quantitativas e computacionais como modelagem matemática, agente-based modeling, e qualitativos como auto-etnografia, pesquisa ação e grounded theory. Outra busca por superar as dicotomias 
entre métodos quantitativos e qualitativos são as perspectivas de triangulação, métodos mistos e multimétodos. Finalmente, destacamos a ampliação do próprio método de meta-síntese, critical realist synthesis, desenvolvido por Brannan, Fleetwood, O’Mahoney e Vincent (2017).

No que se refere ao tema (2) Estudos e temas críticos aparece, ainda em processo de desenvolvimento, discussões sobre emancipação, dialética, crítica, resistência, hegemonia, entre outros. Aqui é importante destacar que dentre as várias fases do realismo crítico, o realismo crítico dialético proposto por Roy Bhaskar se volta para a importância destes temas destacados neste agrupamento. Percebemos que pelo número pequeno de menções ainda é um tema pouco desenvolvido, isto é, os estudos de organizações e gestão ainda não ampliaram o debate para outras fases do realismo crítico de Bhaskar, especialmente, o dialético e menos ainda o da meta-Realidade (Vandenberghe, 2010). Assim, temas como crítica, dialética e emancipação que apesar se serem centrais em várias obras de Bhaskar parece ainda muito poucos explorados pelo campo de estudos realistas crítico em gestão e organizações. A ampliação dos temas críticos pode proporcionar diálogos com o movimento do Critical Management Studies.

O tema (3) Estudos sobre consumo surge como outra possibilidade, especificamente ligada aos estudos de marketing com destaque para pesquisa sobre consumo, percepção dos consumidores, marca, qualidade de serviços, comportamento do consumidor e aceitação. Assim, estes temas clássicos em consumo e marketing também emergem como importantes na agenda de pesquisa a partir do realismo crítico. As (4) Teorias mobilizadas mostram que os debates mobilizam outras teorias seja para contrapor ou complementar como materialismo, realismo agencial, teoria feminista, teoria da atividade e teoria atorrede. Esta última representa um campo amplo de debate dado as divergências existentes com o realismo crítico e, no campo de gestão e organizações se faz relevante já que a teoria ator-rede constitui no Brasil um campo de estudos mais amplo que o realismo crítico. Teorias que tratam de debates específicos também são citadas como lógicas institucionais e a perspectiva da estratégia-como-prática, já bastante consolidada nos estudos sobre estratégia.

No que se refere à (5) Administração pública, vimos que são poucos os trabalhos nessa área a partir do realismo crítico, e, a partir de palavras como accountability e sociedade civil temos uma ampla lacuna de pesquisas na administração pública vista a partir da ontologia do realismo crítico. Adiante, em (6) Temas sociológicos e culturais agrupam questões amplas que são discutidas também em gestão e organizações como: comunicação, cultura, verdade, valores, ação coletiva, ética, comportamento coletivo e criatividade - todos estes ainda de forma bastante incipiente. Finalmente, em (7) Negócios e Gestão foram agrupados palavras relacionadas com estratégia, finanças, responsabilidade social, desenvolvimento sustentável, logística, patentes, competitividade, entre outros. Isso denota uma agenda de pesquisa com estudos que possam abranger as áreas funcionais das organizações. Assim, além de temas críticos, os estudos indicam também potenciais gerenciais do realismo crítico.

\section{Controvérsias na frente de pesquisa}

Ainda na Frente de Pesquisa mapeamos e apresentamos brevemente algumas controvérsias científicas do campo envolvendo o realismo crítico $(\mathrm{RC})$ - consideramos apenas os debates em gestão e organizações e não focamos outros mais amplos como o debate entre Ernesto Laclau e Bhaskar de 1998. Identificamos quatro grandes debates conforme Figura 5. 
Figura 5 - Mapeamento das controvérsias na Frente de Pesquisa

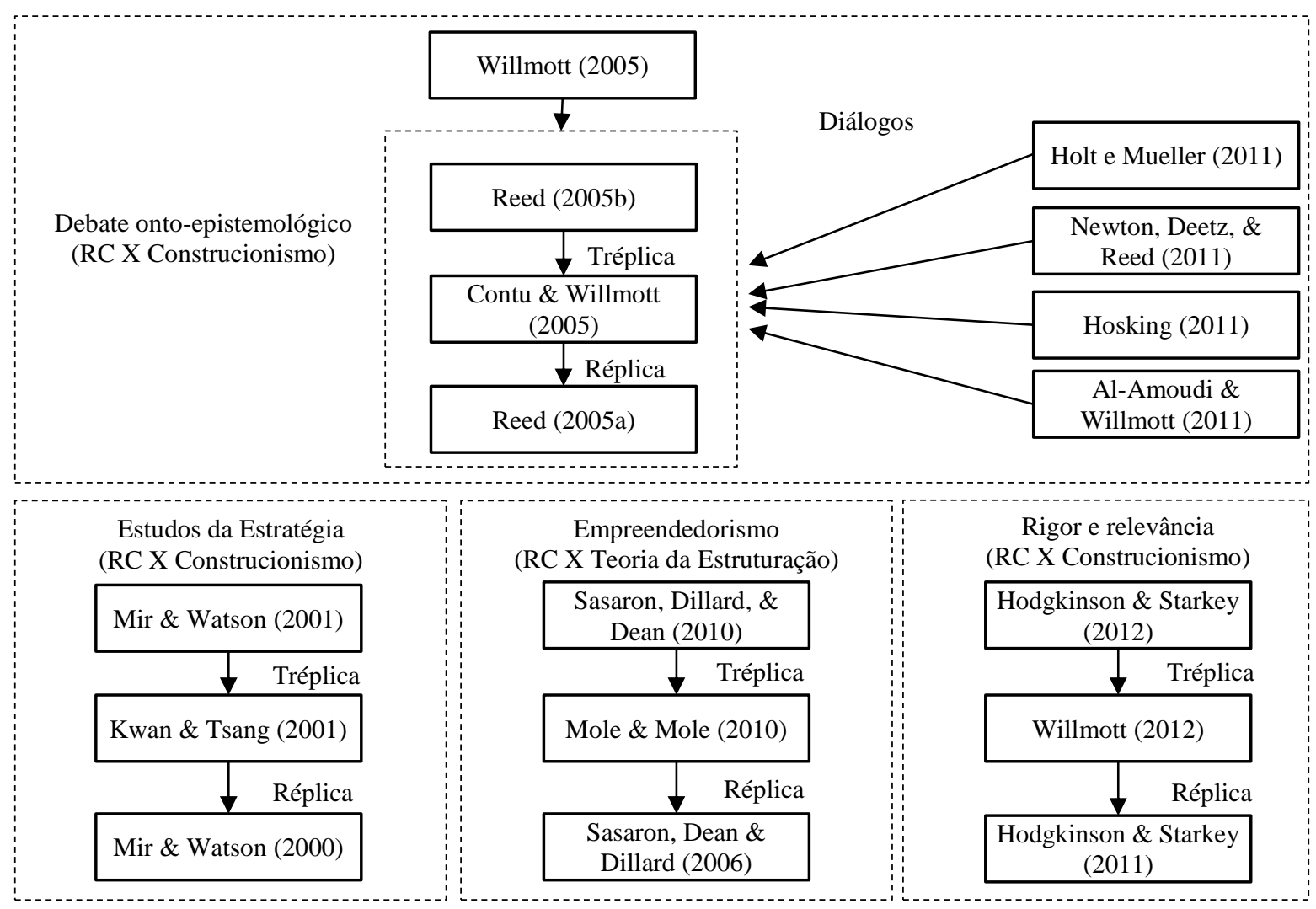

Fonte: Elaborada pelos autores.

A primeira controvérsia, inicia-se com a crítica de Kwan e Tsang (2001) à Mir e Watson (2000) no que se refere à proposta destes últimos autores em promover uma guinada nos estudos em estratégia para a tradição construcionista. Mir e Watson (2000) criticam as ênfases do campo da estratégia, que normalmente desconsidera aspectos críticos. Todavia, Kwan e Tsang (2001) entendem que uma proposta construcionista pode incorrer em variações radicais do construcionismo e no relativismo da análise e oferecem uma visão alternativa a partir do realismo crítico. A tréplica aparece em Mir e Watson (2001).

Em réplica ao texto de Reed (2005a) já apresentado aqui, Contu e Willmott (2005, p. 1646) afirmam que na forma apresentada por Reed a virada realista traz poucas contribuições e questiona: "In what sense does critical realism offer a 'new direction'? And in what direction does it aspire to take us?". Além disso, várias críticas são traçadas girando em torno do questionamento da realist turn. Na tréplica, Reed (2005b) esclarece alguns pontos e amplia o debate. O texto de Willmott (2005) também é reflexo deste debate mesmo não sendo uma réplica. Nesse, o autor defende a abordagem de Laclau e Mouffe como mais coerente do que o realismo crítico. Willmott (2005) compara aspectos teórico-metodológicos do realismo crítico de Bhaskar com a teoria discursiva de Laclau e Mouffe e apresenta argumentos de que esta última apresenta maiores contribuições quando comparada ao realismo crítico sobretudo no que se refere ao comprometimento com a emancipação e a superação de dualismos.

Adiante, após a controvérsia houve elementos que se ampliaram dialogicamente como o texto de AlAmoudi e Willmott (2011) que buscam as convergências entre o construcionismo e o realismo crítico com ênfase na noção de relativismo epistemológico. Por sua vez, Newton, Deetz e Reed (2011) foram organizadores de um número publicado na Organization Studies que promoveu uma síntese e aproximou aspectos do realismo crítico e do construcionismo. Neste número, estão presentes os artigos de AlAmoudi e Willmott (2011), Hosking (2011) e Holt e Mueller (2011) que realizam algumas aproximações. 
A terceira controvérsia mapeada começa quando Mole e Mole (2010) criticam Sasaron, Dean e Dillard (2006) quanto ao estudo da relação entre oportunidade, agência, estrutura e empreendedorismo. Sasaron, Dean e Dillard (2006) propõem um modelo de estudo a partir da teoria da estruturação de Giddens. No entanto, Mole e Mole (2010) discordam de aspectos desta perspectiva e entendem que o realismo crítico, especialmente a perspectiva morfogenética de Archer, oferece um melhor arcabouço para se entender a relação entre empreendedorismo e oportunidade. A tréplica vem com o texto de Sasaron, Dillard e Dean (2010).

A quarta e última controvérsia identificada nasce da crítica de Willmott (2012) à proposta de Hodgkinson e Starkey (2011). Estes últimos argumentam em prol de uma visão realista crítica para pensar a relação entre rigor e relevância. Em resposta, Willmott (2012) indica que a defesa do realismo crítico não é coerente e afirma que corre o risco de desvalorizar abordagens que buscam a emancipação. $\mathrm{Na}$ tréplica, Hodgkinson e Starkey (2012) afirmam que ao considerar a interação de múltiplos mecanismos gerativos, o realismo crítico é compatível com as abordagens científicas voltadas para a emancipação.

Em síntese, identificamos que no campo existem várias controvérsias que em geral estão focadas nas posições realista críticas em oposição ao construcionismo social, vice-versa.

\section{Base intelectual do campo de pesquisa}

Prosseguindo às análises, passamos a avaliar as redes de cocitações de periódicos, autores e referências. Para ampliar o entendimento a respeito dos periódicos, por meio do Citespace foi construída uma rede de cocitações (journal co-citation network). Neste caso, não são considerados periódicos em que os artigos da amostra foram publicados, mas sim os periódicos cocitados pelos 160 artigos analisados. Os 10 primeiros periódicos foram: Academy of Management Review (citado 102 vezes), Organization Studies (90), Organization Science (77), Organization (74), Journal of Management Studies (70), Administrative Science Quarterly (59), Academy of Management Journal (52), Strategic Management Journal (48), Human Relations (42) e MIS Quarterly (42).

Observamos, portanto, que os autores dos 160 artigos delimitados nesta pesquisa citam principalmente artigos dos periódicos Academy of Management Review e Organization Studies. O mais frequente (Academy of Management Review) mesmo não sendo um periódico de divulgação da abordagem do realismo crítico, publicou ao longo de suas edições artigos que são clássicos e são referências "necessárias" para diversos debates. Observamos que o campo ainda foca muito em artigos do próprio campo (gestão e estudos organizacionais) e que periódicos de outras áreas aparecem apenas nas posições $11^{\circ}$ (Sociology; 37 vezes), $12^{\circ}$ (Journal of Critical Realism; 36) e $13^{\circ}$ (American Sociological Review; 35) e outras menos frequentes. O Journal of Critical Realism é um periódico dedicado à publicações sobre realismo crítico, portanto, para além do nosso foco é relevante notar que o realismo crítico no seu processo de institucionalização e "virada" já possui seu próprio periódico especializado - publicado pela Taylor \& Francis desde 1998 (1998-2002: Aletbia; 2002-Atual: Journal of Critical Realism). O periódico é da International Association for Critical Realism (IACR).

No que se refere à rede de autores (author co-citation network) apenas indicamos alguns elementos, visto que será dada ênfase a rede de referências. Os autores que apareceram com maior frequência (somando todas as obras citadas e edições) foram (corte de mais de 25 citações): Archer (150), Bhaskar (145), Sayer (87), Reed (61), Fleetwood (57), Mingers (57), Lawson (41), Tsoukas (38), Ackroyd (37), Danermark (36), Giddens (34), Mutch (32), Easton (30), Fairclough (29), Alvesson (29), Orlikowski (28) e Collier (28).

Um resultado relevante é que Bhaskar, percussor do realismo crítico na filosofia, não é atualmente o autor mais citado no campo, mesmo estando praticamente em "empate técnico" com Archer (que apareceu como a mais citada). De forma rápida, Roy Bhaskar (1944-2014) publicou em 1975 A realist theory of science, fundando esta perspectiva. Para Vandenberghe (2016, p. 179) Bhaskar mostra que "Aqueles/as que confundem nosso conhecimento e modelos de realidade com a própria realidade cometem a falácia epistêmica". Margaret Archer, por sua vez, em Realist social theory: the morphogenetic 
approach apresenta sua própria abordagem realista crítica (Vandenberghe, 2010). Se Bhaskar transitava pela filosofia, Margaret Archer é "a principal representante do realismo crítico na sociologia" (Vandenberghe, 2010, p. 15). Assim, Archer (1995) considera que as relações entre agência e estrutura são fundamentais de um ponto de vista ontológico e somente considerando tais relações é que as análises podem avançar e se sustentar (Vandenberghe, 2010). Cabe menção também a Andrew Sayer (terceiro com maior número de citações), principalmente por ser importante para a popularização do realismo crítico.

Do campo de estudos organizacionais e de gestão, os autores mais citados são Reed e Fleetwood. Outros autores que aparecem citados e fazem parte amplas discussões na filosofia e na ciência social são: Latour, Bourdieu, Foucault, Habermas, Harré (foi orientador de Bhaskar), Searle, Laclau, Harvey, Polanyi, Castells, Peirce e outros. Da administração e estudos organizacionais apareceram também uma diversidade de autores nas discussões: Burrell, Pettigrew, Willmott, Pfeffer, Dimaggio, Whittington, Deetz, Hardy, Mintzberg e outros.

Na Figura 6, por meio da rede de referências (reference co-citation network), é possível identificar os textos centrais do realismo crítico no campo de estudo da gestão e organizações.

Figura 6 - Reference co-citation network

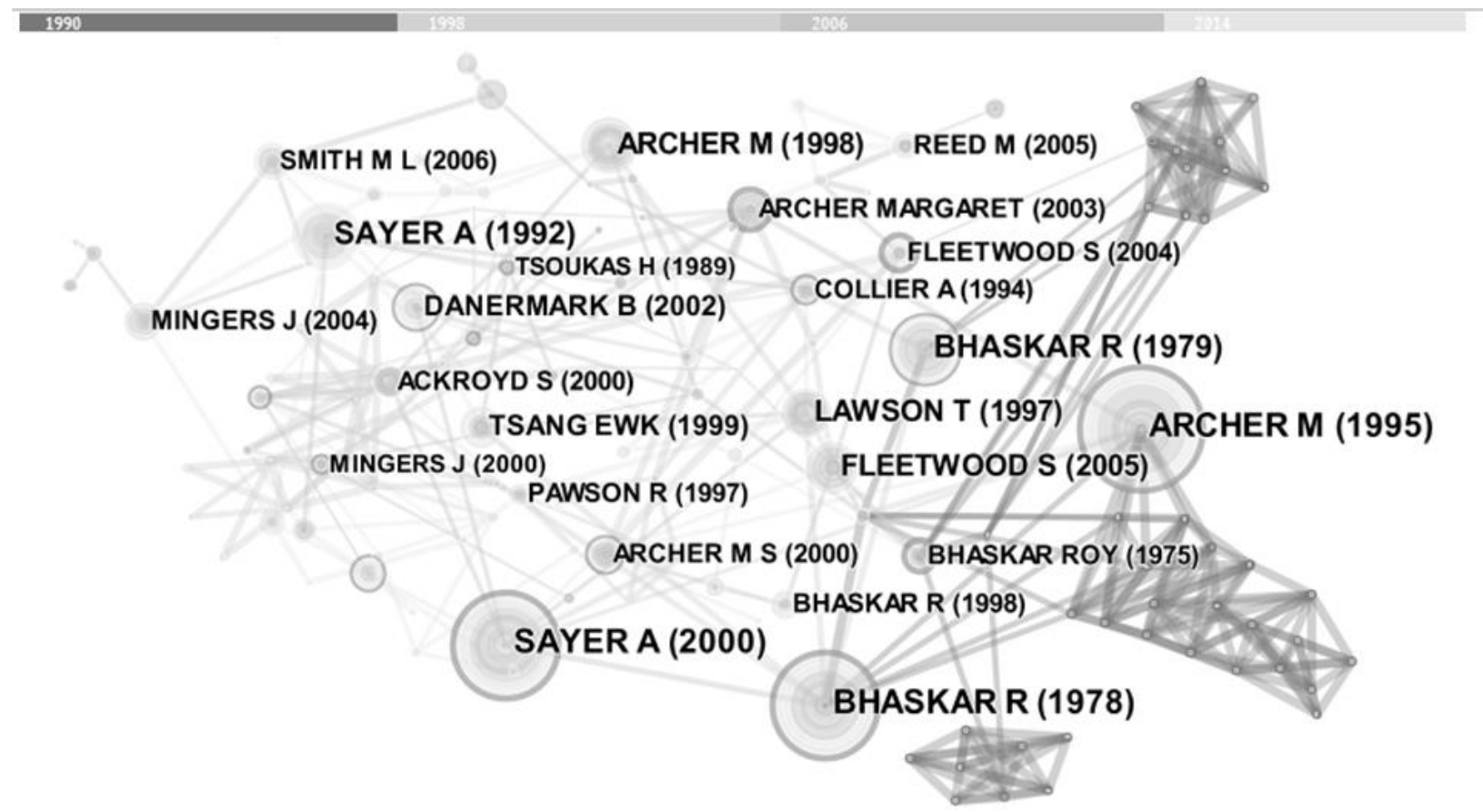

Fonte: Elaborada pelos autores.

$\mathrm{Na}$ rede aparece trabalhos com frequência (citações) igual ou superior à 17. Entretanto, o destaque é apenas para nome do primeiro autor do artigo e o ano de publicação - a autoria e informações mais completas dos 15 trabalhos mais relevantes (com mais de 20 citações) é apresentada na Tabela 4. Para a construção da rede utilizamos dos algoritmos de "poda" Pathfinder e "Pruning Sliced networks" igual à 8 (Chen, 2006). Inicialmente observamos que Archer, Bhaskar e Sayer - conforme indicado também pela rede de cocitações de autores - aparecem como as principais referências do realismo crítico. Inicialmente, observamos que as datas de publicações de livros clássicos da década de 1970 (A realist theory of science é de 1975) até 1990 é coerente com a noção de que a teoria realista contemporânea emerge na década de 1980, em que surge novas tentativas de síntese das relações agência-estrutura. 
Tabela 4 - Referências centrais dos estudos realista-críticos em da gestão e organizações

\begin{tabular}{|c|c|c|c|c|}
\hline Título & Referência & Periódico/Livro & Ano & Cit. \\
\hline Realist social theory: The morphogenetic approach & Archer & Livro & 1995 & 57 \\
\hline 2. A realist theory of science & Bhaskar & Livro & 1978 & 55 \\
\hline Realism and social science & Sayer & Livro & 2000 & 46 \\
\hline $\begin{array}{l}\text { 4. The possibility of naturalism: A philosophical critique of the } \\
\text { contemporary human sciences }\end{array}$ & Bhaskar & Livro & 1979 & 38 \\
\hline 5. Method in social science: a realistic approach & Sayer & Livro & 1992 & 37 \\
\hline 6. Critical realism: essential readings & Archer et al & Livro & 1998 & 32 \\
\hline 7. Economics and reality & Lawson & Livro & 1997 & 32 \\
\hline $\begin{array}{l}\text { 8. Ontology in organization and management studies: } A \text { critical } \\
\text { realist perspective }\end{array}$ & Fleetwood & Organization & 2005 & 30 \\
\hline $\begin{array}{l}\text { 9. Replication and theory development in organizational science: a } \\
\text { critical realist perspective }\end{array}$ & Tsang e Kwan & $\begin{array}{l}\text { Academy of Management } \\
\text { Review }\end{array}$ & 1999 & 26 \\
\hline $\begin{array}{l}\text { 10. Explaining society: an introduction to critical realism in the } \\
\text { social sciences }\end{array}$ & $\begin{array}{l}\text { Danermark e } \\
\text { colaboradores }\end{array}$ & Livro & 2002 & 25 \\
\hline 11. Being human: the problem of agency & Archer & Livro & 2000 & 22 \\
\hline 12. Realist perspectives on management and organisations & $\begin{array}{l}\text { Ackroyd e } \\
\text { Fleetwood }\end{array}$ & Livro & 2000 & 22 \\
\hline 13. Structure, agency and the internal conversation & Archer & Livro & 2003 & 21 \\
\hline $\begin{array}{l}\text { 14. Real-izing information systems: critical realism as an } \\
\text { underpinning philosophy for information systems }\end{array}$ & Mingers & $\begin{array}{l}\text { Information and } \\
\text { Organization }\end{array}$ & 2004 & 21 \\
\hline 15. A realist theory of science & Bhaskar & Livro & 1975 & 21 \\
\hline
\end{tabular}

Fonte: Elaborada a partir do CiteSpace.

Anteriormente já apresentamos um pouco sobre Archer e Bhaskar, aqui enfatizamos apenas que a principal referência do campo é o livro Realist social theory: The morphogenetic approach de Archer publicado em 1995 e seguido por $A$ realist theory of science de Bhaskar. O texto Realism and social science de Andrew Sayer ocupa a terceira posição.

No que se refere a Bhaskar, segundo Vandenberghe (2014, p. 11) "[...] podemos distinguir três ondas: o realismo crítico (primeira onda), o realismo crítico dialético (segunda) e a filosofia da meta-Realidade (terceira)". A primeira é marcada pela sua obra $A$ realist theory of science. $\mathrm{Na}$ segunda (realismo crítico dialético) é destaque a obra Dialetics: the pulse of the freedom de Bhaskar. A terceira é a filosofia da metarealidade com os textos Reflections on meta-reality: transcedence, emancipation and everyday life e Meta-reality: creativity, love and freedom. Aqui observamos ênfase do campo de estudos em gestão e organizações apenas no primeiro momento, isso se revela também nas poucas menções aos debates sobre emancipação e dialética conforme críticas destacadas nas controvérsias e análise das palavras-chave. Portanto, ao adentrar em outras obras de Bhaskar a questão da dialética e da emancipação se tornam mais centrais, possibilitando, inclusive, avançar nas críticas à abordagem.

Observamos também que já existem artigos publicados em gestão e organizações que aparecem entre os textos mais citados na Base Intelectual como Fleetwood (2005), Tsang e Kwan (1999), Mingers (2001) e outros, mostrando que apesar de enfatizar os textos clássicos, os estudos já reconhecem as contribuições do próprio campo.

\section{Caminhos da virada realista crítica}

Convivemos nos estudos da filosofia e sociologia, até mesmo gestão e organizações com uma diversidade de viradas: virada linguística, prática, pragmática, espacial, histórica, pós-moderna, realista e outras. (Vandenberghe \& Corrêa, 2016). Portanto, temos viradas "puras" e "híbridas" que se complementam e que se enfrentam. Cada virada tem como mérito a atenção a elementos que eram pouco estudados por outras como a linguagem, a prática, o significado, o espaço, a história, a ontologia, o cotidiano, entre outras, e, tem como ônus que ao enfatizar uma questão, não raro, se desvia de outras categorias relevantes ou exagera na importância de certos elementos. Daí cada nova virada instalar controvérsias. Além disso, 
cada virada está relacionada com um conjunto de autores, periódicos, temas e capitais científicos que são colocados em movimento. Considerando isso, apresentamos neste artigo como se configura o campo dos estudos sobre gestão e organizações construído a partir do realismo crítico e, portanto, elementos da "virada realista".

Dessa forma, esta pesquisa sistematizou a literatura realista crítica nos estudos sobre gestão e organizações, analisando os possíveis caminhos de uma "virada realista" discutida por Reed (2005a). A pesquisa argumentou também em prol da relevância dessa abordagem filosófica e social enquanto alternativa as posições sobre a realidade próximas ao positivismo e ao construcionismo radical - além disso, faz a chamada para a relevância da ontologia (Reed, 2005a, 2005b). A perspectiva realista crítica contribui para romper nos estudos sobre gestão e organizações com o empiricismo realista dos positivistas e positivistas lógicos, mas, sem cair no relativismo de versões do pós-modernismo e do pósestruturalismo (Fleetwood, 2005; Reed, 2005a).

Esse estudo encontrou a difusão do realismo crítico no campo dos estudos sobre gestão e organizações somente a partir dos anos 2000, a partir da publicação de textos como Reed (2005a) e Fleetwood (2005). Encontramos também diferentes perspectivas do realismo crítico (não é um movimento homogêneo), a hegemonia inglesa deste campo de saber, a relevância das referências de Archer, Bhaskar e Sayer, e, a existência de controvérsias, especialmente, com posições socioconstrucionistas e socioconstrucionistas radicais.

A virada realista, que pelo artigo identificamos que se apresenta como uma proposta alternativa e ainda em consolidação, destaca a questão da ontologia que estava sendo apagada pelas perspectivas focadas somente na epistemologia e, nisso concebe que existe uma realidade independente da cognição humana e do seu conhecimento, portanto, considera uma dimensão intransitiva ou ontológica com estruturas e mecanismos que existem independentemente de nosso conhecimento e uma dimensão transitiva (conceitos científicos, leis e teorias) que é socialmente construída: combina realismo ontológico com o relativismo epistemológico. Nesse sentido, o realismo crítico se mostra como uma abordagem aberta para aproximações conceituais e debates teóricos com outras concepções.

Este texto argumenta que o realismo crítico oferece potenciais para o entendimento e explicação da relação entre conhecimento e objeto, a estratificação da realidade, a ciência como prática social, os conceitos de entidades, poderes e responsabilidades, eventos e estruturas, ontologia e epistemologia, a emergência e efeitos causais. Também supera paradoxos entre a utilização de um ou mais métodos, bem como a questão do envolvimento do pesquisador e da interpretação (que sempre está presente e nunca é neutra). Finalmente, procura pela abdução superar as limitações da indução e da dedução e dos focos unilaterais na relação agência-estrutura encontrados nas teorias sociais, dentre outras contribuições.

Como aqui também lembrado, cada virada, além de seus ganhos, tem que lidar com sua apreensão limitada (transitiva) da realidade e com as controvérsias e críticas que movem. No que tange as críticas, destacamos que Fleetwood (2005), dentre outros, generalizam o entendimento de virada pós-moderna como síntese das viradas cultural, linguística, pós-estrutural e outras. E que essas viradas precisam ser separadas em seus pontos comuns e divergentes. Outra crítica a visão realista crítica diz respeito ao tratamento limitado da noção de falibilismo e relativismo em decorrência da ênfase na ontologia e nas contradições decorrentes do dizer o que a realidade é e o que ela não é (Cruickshank, 2010). A crítica de Cruickshank (2010) à Bhaskar e à Archer indica que para justificar suas afirmações em termos de ontologia, os realistas críticos caem em uma série de problemas.

Outras contraposições aparecem nas leituras de Laclau, Mouffe e nos autores (Willmott, 2005), em geral, focados na virada pós-moderna e, por outro lado, em marxistas que criticaram concepções mais recentes de Bhaskar. Existem ainda debates sobre a distinção entre as dimensões transitiva e intransitiva e até que ponto não cai em uma dualidade (Vandenberghe, 2010). As críticas são elementos importantes a serem 
enfrentadas: é importante para o desenvolvimento do próprio campo. Existem outras críticas que podem ser acessadas na literatura que mapeamos.

Ainda nesta pesquisa indicamos uma agenda de pesquisas focada em possíveis contribuições para estudos de gestão e organizações focadas nos temas: Perspectivas e métodos de pesquisa, Estudos e temas críticos, Estudos sobre consumo, Teorias mobilizadas, Administração pública, Temas sociológicos e culturais e Negócios e Gestão. Por fim, especificamos outros direcionamos de pesquisa com destaque para: sociomaterialidade, emergência, entidades, poderes, transitividade e intransitividade, mecanismos e efeitos causais do discurso, abdução, domínios da realidade, modelo transformacionais da ação social de Bhaskar, modelo morfogenético de Archer, agência e estrutura, interdisciplinaridade, emergência e fundamentação, estudos voltados para a crítica explanatória e emancipação e a descrição da matriz epistêmica do realismo crítico, além de estudos voltados ao campo da administração pública e suas problemáticas e, a continuação de diálogos entre realista-críticos e socioconstrucionistas.

Esperamos que o estudo auxilie pesquisadores a trilhar a busca pela ontologia indicada pelo realismo crítico, considerando evidentemente que não se trata da primeira, nem da última virada teórica incentivada ou apoiada no campo, dado que ela se constrói na dimensão transitiva do conhecimento. Se para Pimentel (2012, p. 44) o realismo crítico é um "tema de ponta" nas pesquisas em sociologia e nos estudos em organizações ainda é "relativamente recente e pouco difundido", nosso estudo permitiu indicar que no campo dos estudos em gestão e organizações esta perspectiva já trilhou um caminho considerável e apresenta elementos de uma "virada" em consolidação.

\section{Referências}

Al-Amoudi, I., \& Willmott, H. (2011). Where constructionism and critical realism converge: Interrogating the domain of epistemological relativism. Organization Studies, 32(1), 27-46. http://dx.doi.org/10.2139/ssrn.1781119

Archer, M. (1995). Realist Social Theory. The Morphogenetic Approach. Cambridge, Cambridge University Press.

Bhaskar, R. (1978). A Realist Theory of Science. Brighton: Harvester-Wheatsheaf.

Brannan, M. J., Fleetwood, S., O’Mahoney, J., \& Vincent, S. (2017). Critical Essay: Meta-analysis: A critical realist critique and alternative. Human Relations, 70(1), 11-39. http://dx.doi.org/10.1177/0018726716674063

Chen, C. (2004). Searching for intellectual turning points: Progressive knowledge domain visualization. PNAS, 101(suppl 1), 5303-5310. http://dx.doi.org/10.1073/pnas.0307513100

Chen, C. (2006). CiteSpace II: Detecting and visualizing emerging trends and transient patterns in scientific literature. JASIST, 57(3), 359-377. http://dx.doi.org/10.1002/asi.20317

Contu, A., \& Willmott, H. (2005). You spin me round: The realist turn in organization and management studies. Journal of Management Studies, 42(8), 1645-1662. http://dx.doi.org/10.1111/j.14676486.2005.00560.x

Cruickshank, J. (2010). Knowing Social Reality: A Critique of Bhaskar and Archer's Attempt to Derive a Social Ontology from Lay Knowledge. Philosophy of the Social Sciences, 40(4), 579-602. http://dx.doi.org/10.1177/0048393109340664

Easton, G. (2010). Critical realism in case study research. Industrial Marketing Management, 39(1), 118-128. http://dx.doi.org/10.1016/j.indmarman.2008.06.004 
Fairclough, N. (2005). Peripheral vision: Discourse analysis in organization studies: The case for critical realism. Organization Studies, 26(6), 915-939. http://dx.doi.org/10.1177/0170840605054610

Fleetwood, S. (2005). Ontology in organization and management studies: A critical realist perspective. Organization, 12(2), 197-222. http://dx.doi.org/10.1177/1350508405051188

Fleetwood, S. (2009). The ontology of things, properties and powers. Journal of Critical Realism, 8(3), 343366. http://dx.doi.org/10.1558/jocr.v8i3.343

Hodgkinson, G. P., \& Starkey, K. (2011). Not simply returning to the same answer over and over again: reframing relevance. British Journal of Management, 22(3), 355-369. http://dx.doi.org/10.1111/j.14678551.2011.00757.x

Hodgkinson, G. P., \& Starkey, K. (2012). Extending the foundations and reach of design science: further reflections on the role of critical realism. British Journal of Management, 23(4), 605-610. http://dx.doi.org/10.1111/1467-8551.12001

Holt, R., \& Mueller, F. (2011). Wittgenstein, Heidegger and drawing lines in organization studies. Organization Studies, 32(1), 67-84. http://dx.doi.org/10.1177/0170840610394299

Hosking, D. M. (2011). Telling tales of relations: Appreciating relational constructionism. Organization Studies, 32(1), 47-65. http://dx.doi.org/10.1177/0170840610394296

Kwan, K. M., \& Tsang, E. W. (2001). Realism and constructivism in strategy research: A critical realist response to Mir and Watson. Strategic Management Journal, 22(12), 1163-1168. http://dx.doi.org/10.1002/smj.199

Laclau, E., \& Bhaskar, R. (1998). Discourse theory vs critical realism. Alethia, 1(2), 9-14. http://doi.org/10.1558/aleth.v1i2.9

Leca, B., \& Naccache, P. (2006). A critical realist approach to institutional entrepreneurship. Organization, 13(5), 627-651. http://dx.doi.org/10.1177/1350508406067007

Mingers, J. (1992). Criticizing the phenomenological critique-autopoiesis and critical realism. Systems Practice, 5(2), 173-180.

Mingers, J. (2001). Combining IS research methods: towards a pluralist methodology. Information Systems Research, 12(3), 240-259.

Mir, R., \& Watson, A. (2000). Strategic management and the philosophy of science: The case for a constructivist methodology. Strategic Management Journal, 941-953.

Mir, R., \& Watson, A. (2001). Critical realism and constructivism in strategy research: toward a synthesis. Strategic management joumal, 22(12), 1169-1173.

Mole, K. F., \& Mole, M. (2010). Entrepreneurship as the structuration of individual and opportunity: A response using a critical realist perspective: Comment on Sarason, Dean and Dillard. Journal of Business Venturing, 25(2), 230-237.

Newton, T., Deetz, S., \& Reed, M. (2011). Responses to social constructionism and critical realism in organization studies. Organization Studies, 32(1), 7-26.

Nightingale, P. (1998). A cognitive model of innovation. Research Policy, 27(7), 689-709. http://dx.doi.org/10.1016/S0048-7333(98)00078-X 
Pimentel, T. D. (2012). Espaço, Identidade e Poder: esboço de uma teoria morfogenética e morfostática para a sociologia das organizações (Tese de doutorado). Universidade Federal de Juiz de Fora, Juiz de Fora, MG, Brasil.

Pimentel, T. D. (2014). Realismo crítico nos estudos organizacionais: notas introdutórias sobre seus fundamentos filosóficos. Farol, 1(2), 609-656.

Pinto, C. F., Serra, F. R., \& Ferreira, M. P. (2014). A bibliometric study on culture research in International Business. BAR-Braqilian Administration Review, 11(3), 340-363. http://dx.doi.org/10.1590/18077692bar2014309

Prado, J. W., de Castro Alcântara, V., de Melo Carvalho, F., Vieira, K. C., Machado, L. K. C., \& Tonelli, D. F. (2016). Multivariate analysis of credit risk and bankruptcy research data: a bibliometric study involving different knowledge fields (1968-2014). Scientometrics, 106(3), 1007-1029. http://dx.doi.org/10.1007/s11192-015-1829-6

Reed, M. (1997). In praise of duality and dualism: rethinking agency and structure in organizational analysis. Organization Studies, 18(1), 21-42.

Reed, M. (2001). Organization, trust and control: a realist analysis. Organization Studies, 22(2), 201-228. http://dx.doi.org/10.1177/0170840601222002

Reed, M. (2005a). Reflections on the 'realist turn'in organization and management studies. Journal of Management Studies, 42(8), 1621-1644.

Reed, M. (2005b). Doing the Loco-Motion: Response to Contu and Willmott's Commentary on 'The Realist Turn in Organization and Management Studies'. Journal of Management Studies, 42(8), 1663-1673. http://dx.doi.org/10.1111/j.1467-6486.2005.00561.x

Sarason, Y., Dean, T., \& Dillard, J. F. (2006). Entrepreneurship as the nexus of individual and opportunity: A structuration view. Journal of Business Venturing, 21(3), 286-305. http://dx.doi.org/10.1016/j.jbusvent.2005.02.007

Sarason, Y., Dillard, J. F., \& Dean, T. (2010). How can we know the dancer from the dance?: Reply to "Entrepreneurship as the structuration of individual and opportunity: A response using a critical realist perspective".(Mole and Mole, 2008). Journal of Business Venturing, 25(2), 238-243. http://dx.doi.org/10.1016/j.jbusvent.2008.06.003

Sayer, A. (2000). Características-chave do Realismo Crítico na prática: um breve resumo. Estudos de Sociologia. Revista do Programa de Pós-Graduação em Sociologia da UFPE, 6(2), 7-32.

Strong, D. M., \& Volkoff, O. (2010). Understanding Organization-Enterprise System Fit: A Path to Theorizing the Information Technology Artifact. MIS Quarterly, 34(4), 731-756.

Tsang, E. W. (2014). Case studies and generalization in information systems research: A critical realist perspective. The Journal of Strategic Information Systems, 23(2), 174-186. http://dx.doi.org/10.1016/j.jsis.2013.09.002

Tsang, E. W., \& Kwan, K. M. (1999). Replication and theory development in organizational science: A critical realist perspective. Academy of Management Review, 24(4), 759-780. http://dx.doi.org/10.2307/259353

Vandenberghe, F. (2010). Teoria social realista. Belo Horizonte: UFMG.

Vandenberghe, F. (2016). Obituário: Roy Bhaskar (1944-2014). Polifonia, 23(33), 179-182. 
Vandenberghe, F., \& Corrêa, D. S. (2016). As "viradas" nas ciências humanas. Recuperado de http://www.iesp.uerj.br/wp-content/uploads/2016/08/As- $\%$ E2\%80\%9 Cviradas $\%$ E2\%80\%9D-nasci $\%$ C3\%AAncias-humanas.pdf

Venkatesh, V., Brown, S. A., \& Bala, H. (2013). Bridging the qualitative-quantitative divide: Guidelines for conducting mixed methods research in information systems. MIS Quarterly, 37(1), 21-54.

Willmott, H. (2005). Theorizing contemporary control: Some post-structuralist responses to some critical realist questions. Organization, 12(5), 747-780.

Willmott, H. (2012). Reframing relevance as 'social usefulness': A comment on Hodgkinson and Starkey's 'Not simply returning to the same answer over and over again'. British Journal of Management, 23(4), 598604.

Zinkhan, G. M., \& Hirschheim, R. (1992). Truth in marketing theory and research: an alternative perspective. The Journal of Marketing, 56(2), 80-88. 